\title{
François Desrues, Les marguerites françoises ou thresor des fleurs du bien dire
}

\section{Daniela Dalla Valle}

\section{(2) OpenEdition}

1 Journals

\section{Edizione digitale}

URL: http://journals.openedition.org/studifrancesi/35997

DOI: 10.4000/studifrancesi.35997

ISSN: 2421-5856

\section{Editore}

Rosenberg \& Sellier

\section{Edizione cartacea}

Data di pubblicazione: 1 juillet 2005

Paginazione: 153

ISSN: 0039-2944

\section{Notizia bibliografica digitale}

Daniela Dalla Valle, «François Desrues, Les marguerites françoises ou thresor des fleurs du bien dire», Studi Francesi [Online], 145 (XLIX | I) | 2005, online dal 30 novembre 2015, consultato il 20 avril 2021 URL: http://journals.openedition.org/studifrancesi/35997 ; DOI: https://doi.org/10.4000/studifrancesi. 35997

Questo documento è stato generato automaticamente il 20 avril 2021.

\section{(c) $(1) \ominus$}

Studi Francesi è distribuita con Licenza Creative Commons Attribuzione - Non commerciale - Non opere derivate 4.0 Internazionale. 


\title{
François Desrues, Les marguerites françoises ou thresor des fleurs du bien dire
}

\author{
Daniela Dalla Valle
}

\section{NOTIZIA}

FRANÇOIS DESRUES, Les marguerites françoises ou thresor des fleurs du bien dire, Fac-similé de l'édition de T. Reinsart, Rouen, 1609, a cura di Ch.-O. STIKER-METRAL, Reims, Publication du Centre de Recherche sur la Transmission des Modèles Littéraires et Esthétiques, 2003, pp. XXI +556 .

1 Il volume riproduce anastaticamente le Marguerites françoises, famosissima raccolta - in forma di dizionario - di sentenze, metafore, estratti romanzeschi, che testimoniano un certo tipo della cultura letteraria dell'inizio del Seicento. Il testo è preceduto da un'introduzione che fa il punto sull'opera, sull'autore, sulla costituzione delle Marguerites, sulla loro funzione, e ne segnala l'importanza attuale, come repertorio di espressioni e clichés della prosa francese stile Nervèze. Completa l'introduzione l'elenco delle varie edizioni e una bibliografia critica. 